\title{
Avandia outcome may signal change in epidemiologists' sway
}

Next month, the Obama-era US Food and Drug Administration (FDA) will confront what is likely to be the most defining moment in its short history. In a public meeting scheduled for mid-July, a committee of external experts will advise agency leaders - who may or may not accept their advice-on whether to ban a controversial diabetes drug implicated in causing heart attacks, when an equally effective competitor is also on the market, minus the heart attack risks.

The extensive media coverage and drawn-out agency decision making over the blockbuster drug, Avandia (rosiglitazone), made by UK-based GlaxoSmithKline, point to an increasingly noticeable power struggle within the agency. That struggle pits government epidemiologists who track the safety of drugs once they are on the market against their colleagues in an FDA division five times as large where regulators approve new drugs. Critics argue that these regulators are prone to inaction when drugs they have approved turn out to be unsafe. Those on the other side of the argument retort that every drug presents a balance of risks and benefits, and that the agency should not hastily restrict marketed drugs without compelling new evidence of harm to patients.

Two FDA epidemiologists who surveyed the literature reported in 2008 that roughly 500 excess heart attacks would be prevented each month if every diabetic taking Avandia were switched to its only direct competitor, Actos (pioglitazone), made by Takeda Pharmaceutical in Osaka, Japan. They recommended Avandia's immediate removal from the market.

The epidemiologists, David Graham and Kate Gelperin, also called for a halt in a large ongoing trial comparing Avandia head to head with Actos, which shows no evidence of boosting heart attack risk. (Both drugs do cause some patients to develop congestive heart failure, a distinct condition from heart attack.) They said that the trial, called TIDE, is "unethical and exploitative" because it puts patients in the Avandia arm at unacceptable risk, given the availability of a safer, equally effective, alternative. The agency has not acted on either recommendation.

After the epidemiologists' conclusions were publicized in a February report compiled by staff of the Senate Finance Committee-whose senior Republican, Senator Charles Grassley, has taken a keen interest in the policing of drugs and drug companies-FDA Commissioner Margaret Hamburg told senators that the agency will exhaustively consider all of the available evidence on the cardiovascular safety of Avandia. She added that, on the basis of this review and input from a double-barreled advisory committee of diabetes and drug safety experts, the FDA would make a decision about the drug's future.

For the new FDA, "Avandia is certainly a great test case," says Steven Nissen, a cardiologist at the Cleveland Clinic in Ohio, whose 2007 meta-analysis in The New England Journal of Medicine (NEJM) first publicly reported an increased heart attack risk with Avandia ( $N$. Engl. J. Med. 356, 2457-2471, 2007). "Will the FDA reconfigure itself as a public health agency, or will it continue to primarily be in the business of promoting pharmaceuticals?"

Other experts say that the black-and-white choice presented by Nissen is oversimplified and that data on Avandia's heart attack risks are inconclusive, making it important for the TIDE trial to proceed.

"While the original [NEJM] article still raises concerns, subsequent data have not further elevated that concern," says David Kendall, the chief scientific and medical officer of the American Diabetes Association (ADA). The ADA has not changed the position on Avandia it adopted after the publication of the 2007 NEJM article. It advised patients on the drug to continue taking it or to consult with their physicians if the lack of clarity on Avandia's heart risks concerns them.

Meredith Wadman, Washington DC

\section{Diabetes drug woes spell trouble for the entire drug family}

Although the final fate of the blockbuster diabetes drug Avandia (rosiglitazone) remains to be determined later this year by the US Food and Drug Administration, the damage to the family of 'PPAR-gamma ligand' drugs to which it belongs has already largely been done.

Development of such drugs is losing support: "what we have heard back from drug companies is that, if it has the word 'PPAR' in it, it's dead," says Bruce Spiegelman, a cell biologist at the Dana-Farber Cancer Institute in Boston.

PPAR-gamma ligands act on a receptor located in the cell nucleus called peroxisome proliferator-activated receptor (PPAR) gamma, which regulates fatty acid storage and glucose metabolism. The effect of the drugs' binding is to lower patients' blood sugar concentrations.

Elevated blood sugar is, of course, the culprit that does widespread damage in diabetes. And there's no question that both Avandia and its competitor, Actos (pioglitazone), are effective at controlling blood sugar. The problem has been in the side effects that both drugs also induce. Key among them are weight gain, a serious problem in a patient population that already tends to obesity, and fluid retention known as edema. Heart failure is also a serious risk.

Terry Maratos-Flier, a diabetologist at Harvard Medical School in Boston, says that the weight gain was such a problem for some of her patients that she stopped prescribing Avandia, even before reports of its heart attack risks became public. "People with type 2 diabetes usually have [the disease] because they are obese. So, in effect, you are giving a drug that is contributing to the obesity," she says.

The further finding in 2007 (see "Avandia outcome may signal change in epidemiologists' sway") that Avandia boosts heart attack risks just added to the troubling side-effect profile, causing many drug companies to shelve efforts to develop next-generation PPAR-gamma drugs.

"They're wary," says Spiegelman, whose lab first described the function of PPAR-gamma. However, he adds, he has recently elucidated two different mechanisms by which PPAR-gamma ligands exert their biological effects. This means, in principle, that drugs could be developed to exert only blood sugar-improving effects without the undesirable side effects.

But many are skeptical that big pharmaceutical companies can be lured back into the fold. "The safety bar now has been raised so high, and PPARs are so tainted as a class, that drug companies just aren't working in the area anymore," says Steven Kliewer, a professor of molecular biology at the University of Texas Southwestern Medical Center in Dallas, who serves on the scientific advisory board of InteKrin Therapeutics, a Los Altos, Californiabased company that is developing a nextgeneration PPAR-gamma ligand.

That has left it to scattered biotechs, such as InteKrin and Metabolex, based across the San Francisco Bay in Hayward, to take forward a next generation of selective PPAR-gamma agonists. They are banking that their compounds, both in phase 2 trials for diabetes, will deliver the goods without bad side effects.

Meredith Wadman, Washington, DC 